\title{
Validating numerical simulations of snow avalanches using dendrochronology: the Cerro Ventana event in Northern Patagonia, Argentina
}

\author{
A. Casteller ${ }^{1,2}$, M. Christen ${ }^{2}$, R. Villalba ${ }^{1}$, H. Martínez $^{3}$, V. Stöckli ${ }^{2}$, J. C. Leiva ${ }^{1}$, and P. Bartelt ${ }^{2}$ \\ ${ }^{1}$ Instituto Argentino de Nivología, Glaciología y Ciencias Ambientales IANIGLA, CCT Mendoza, CONICET, C.C. 330, \\ 5500 Mendoza, Argentina \\ ${ }^{2}$ WSL, Swiss Federal Institute for Snow and Avalanche Research SLF, Flüelastrasse 11, CH-7260 Davos Dorf, Switzerland \\ ${ }^{3}$ IDEPRN, Facultad de Ingeniería UNCuyo, CONICET, C.C. 405, 5500 Mendoza, Argentina
}

Received: 6 December 2007 - Revised: 24 April 2008 - Accepted: 24 April 2008 - Published: 8 May 2008

\begin{abstract}
The damage caused by snow avalanches to property and human lives is underestimated in many regions around the world, especially where this natural hazard remains poorly documented. One such region is the Argentinean Andes, where numerous settlements are threatened almost every winter by large snow avalanches. On 1 September 2002, the largest tragedy in the history of Argentinean mountaineering took place at Cerro Ventana, Northern Patagonia: nine persons were killed and seven others injured by a snow avalanche. In this paper, we combine both numerical modeling and dendrochronological investigations to reconstruct this event. Using information released by local governmental authorities and compiled in the field, the avalanche event was numerically simulated using the avalanche dynamics programs AVAL-1D and RAMMS. Avalanche characteristics, such as extent and date were determined using dendrochronological techniques. Model simulation results were compared with documentary and tree-ring evidences for the 2002 event. Our results show a good agreement between the simulated projection of the avalanche and its reconstructed extent using tree-ring records. Differences between the observed and the simulated avalanche, principally related to the snow height deposition in the run-out zone, are mostly attributed to the low resolution of the digital elevation model used to represent the valley topography. The main contributions of this study are (1) to provide the first calibration of numerical avalanche models for the Patagonian Andes and (2) to highlight the potential of Nothofagus pumilio tree-ring
\end{abstract}

Correspondence to: A. Casteller

(casteller@lab.cricyt.edu.ar) records to reconstruct past snow-avalanche events in time and space. Future research should focus on testing this combined approach in other forested regions of the Andes.

\section{Introduction}

In Argentina and other countries located in middle to high latitudes in the Southern Hemisphere, the risk associated with snow avalanches in mountainous regions is highly significant; however, avalanche hazard maps are rare. A few ski resorts and heavily-traveled mountain passes are exceptions to this rule (Leiva and Martínez, 1998, 2006). Three main factors explain this lack of avalanche hazard assessments: (1) few or incomplete avalanche cadastres; (2) scarce, fragmentary and non-homogeneous weather and snow accumulation records (Masiokas et al., 2006); and (3) avalanche dynamics calculations have seldom been used to predict hazard zones.

One way to circumvent the uncertainty of avalanche hazard zones is to apply numerical models to predict avalanche runout. Numerical avalanche models developed in Europe, such as AVAL-1D and RAMMS, are currently being tested in key sites in the Andes (Leiva et al., 2007, 2008). However, their final implementation is hampered by the scarcity of calibration data. In addition to the crucial step of accurately identifying avalanche release areas (Maggioni and Gruber, 2003), friction parameters used by the models must be adjusted to local terrain and snow conditions (Furdada et al., 2002). This calibration process can be conducted regionally by simulating snow-avalanche events for which the location and dimension of the release area are known and

Published by Copernicus Publications on behalf of the European Geosciences Union. 


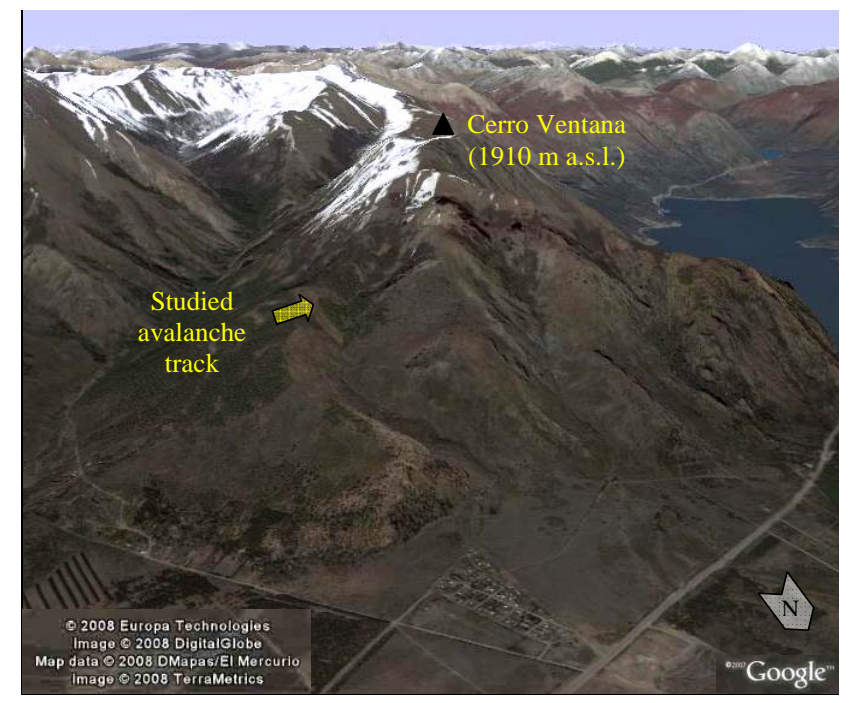

Fig. 1. Three dimensional satellite image of the study site at Cerro Ventana, in the vicinity of the city of San Carlos de Bariloche, Río Negro. The yellow arrow indicates the investigated avalanche track. Image source: Google Earth (permission request \# 242431704).

the exact position of the run-out zone has been determined. However, this information is generally missing for the Andes. One possibility for overcoming this problem is to apply dendrochronological methods.

Dendrochronology is a powerful tool for reconstructing the past occurrence of natural hazards, such as snow avalanches (e.g. Burrows and Burrows, 1976; Carrara, 1979), debris flows (e.g. Hupp, 1984; Bollschweiler et al., 2007) and rockfall activity (e.g. Butler et al., 1986; Stoffel et al., 2005). Tree-ring based records of past avalanche activity extend in many cases for several centuries and have annual resolution. These dendrochronological archives are very useful for establishing avalanche chronologies in undocumented areas or to complement chronologies in areas with short or fragmentary records.

In this study we couple numerical models and dendrochronological analyses in order to reconstruct the avalanche event related to the largest tragedy in the history of Argentinean mountaineering: on 1 September 2002, nine people were killed and seven injured when a large snow avalanche released at Cerro Ventana, near the city of San Carlos de Bariloche. A detailed study of the event was conducted by local governmental authorities to identify the causes of the accident. As a result, an accurate determination of the location and size of the avalanche release area, the height of the snow removed at several points across the release area, and the length and width of the entire avalanche were documented. Daily records of temperature and precipitation, together with snow-profile data, were obtained from a nearby ski resort for the days immediately before and after the event. This information, which is required for running

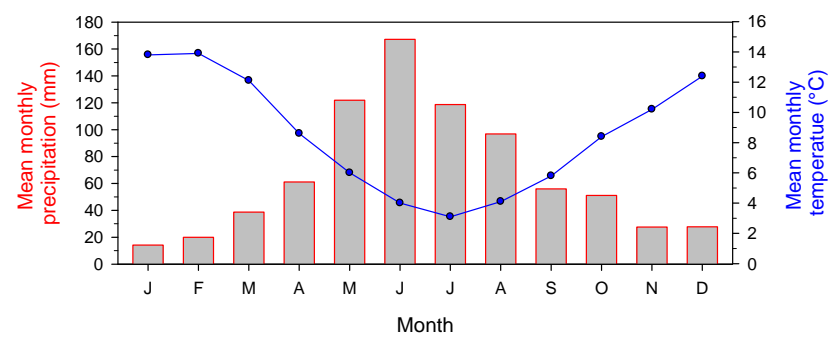

Fig. 2. Mean monthly precipitation (1984-2001) and mean monthly temperature (1984-2000), measured in the city of San Carlos de Bariloche, $7.9 \mathrm{~km}$ northeast of the study area. Source: Instituto Nacional de Tecnología Agropecuaria.

numerical avalanche simulations, is not available for most events recorded along the Andes.

In addition, the avalanche track is partly forested by Nothofagus pumilio trees, which allowed us to recover complementary spatial and temporal information regarding avalanche activity at the site based on different tree-ring indicators, including: (a) scars, (b) abrupt growth changes, (c) eccentricity variations in the wood and (d) tree mortality. Documentary and dendrochronological evidences were used in combination to adjust the friction coefficients applied in the numerical avalanche simulations, thus validating for the first time avalanche models in the Patagonian Andes. Moreover, the opportunity to test different sampling strategies and tree-ring indicators of Nothofagus pumilio in an avalanchedocumented site allowed us to prove the potential of this tree species for reconstructing past avalanche events.

\section{Study area}

The studied avalanche track is located on the southeastfacing slope of Cerro Ventana (also known as Cerro de la Ventana; $1910 \mathrm{~m}$ a.s.1.), $7.9 \mathrm{~km}$ southeast from the city of San Carlos de Bariloche, Río Negro, Argentina (Fig. 1). The site $\left(41^{\circ} 12^{\prime} 36^{\prime \prime} \mathrm{S}, 71^{\circ} 22^{\prime} 32^{\prime \prime} \mathrm{W}\right)$ is $20 \mathrm{~km}$ west of the forest-steppe ecotone and $43 \mathrm{~km}$ east of the continental divide, which in this sector of the Andes is coincident with the border between Argentina and Chile.

Total annual precipitation (1984-2001) and mean annual temperature (1984-2000), both measured by the Instituto Nacional de Tecnología Agropecuaria in San Carlos de Bariloche, are $801 \mathrm{~mm}$ and $8.5^{\circ} \mathrm{C}$, respectively (Fig. 2). Sixtytwo percent of the total precipitation occurs between May and August; at elevations above $1000-1100 \mathrm{~m}$ this precipitation typically occurs as snow.

Austrocedrus chilensis (D. Don) Pic. Sern. et Bizzarri is the dominant tree species at lower-elevations in the Cerro Ventana. Further up on the slopes, Nothofagus antarctica (G. Forster) Oerst. and particularly Nothofagus pumilio (Poepp. et Endl.) Krasser dominate. At the avalanche 
run-out area and especially within the margins of the vegetated avalanche track, $N$. pumilio becomes the dominant or even exclusive tree species. The treeline at Cerro Ventana is located at approximately $1800 \mathrm{~m}$. According to Holtmeier (1973) and Norton and Schönenberger (1984), Nothofagus trees exists close to treeline in a small, stunted, krummholz-type form.

Concerning the geology, the Cerro Ventana corresponds structurally to an Oligocene folding (Paleogene period, Cenozoic), where the Ventana formation outcrops. This formation is composed of lavas and andesitic, rhyolitic and basaltic pyroclastic rocks. Marine and continental conglomerates and sandstones containing invertebrate and plant fossils are also present in the local stratigraphy.

The avalanche track at the release area has a slope angle of $39.7^{\circ}$, which is well-within the $28^{\circ}-50^{\circ}$ slope-angle range that defines a potential avalanche release zone (Perla and Martinelli, 1978; Salm, 1982). The mean slope angles measured along the avalanche track and at the run-out zone are $23^{\circ}$ and $19^{\circ}$, respectively. Another small release area, which flows into the same corridor, is located to the east of our zone (Fig. 3). However, as no historical records exist for past avalanches in this area, our research focuses on the westernmost release zone. The tragic 2002 avalanche released $120 \mathrm{~m}$ below the summit of Cerro Ventana. According to an evaluation committee composed of local governmental authorities and several avalanche experts (Bustos et al., 2003), the avalanche was triggered by overburden on a wet slab of snow. The avalanche incorporated the hikers in the flow and transported them approximately $450 \mathrm{~m}$ into a narrow corridor. Field observations provided by members of the rescue team indicated that the amount of snow deposited in the runout zone of the avalanche reached $7 \mathrm{~m}$.

The climatic conditions of the days preceding the 2002 avalanche are crucial for understanding the causes of the event. First, precipitation in the form of rain occurred at high altitudes (i.e. above $2000 \mathrm{~m}$ ) two days before the accident. Second, air temperatures measured at the elevation of the release area remained above $0^{\circ} \mathrm{C}$ during 50 consecutive hours prior to the accident. Together, these factors resulted in a highly unstable snow pack. Snow profiles conducted at $1600 \mathrm{~m}$ (31 August) and $1980 \mathrm{~m}$ (5 September) at the Cerro Catedral ski resort indicate the presence of a weak snow layer $40 \mathrm{~cm}$ below the surface and a crust within the first few centimeters of the surface, further confirming the instability of the snow pack prior to the event.

\section{Material and methods}

\subsection{Dendrochronological sampling procedures}

To test the utility of N. pumilio for reconstructing the 2002 Cerro Ventana event we sampled seven trees exhibiting clear evidence of past avalanche disturbance, such as broken

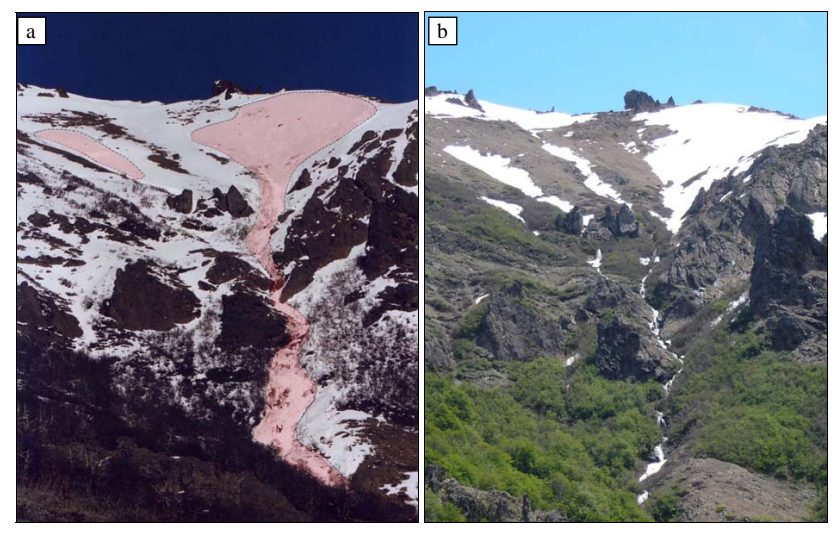

Fig. 3. Photographs of the studied avalanche track taken (a) in September 2002 a few days after the event and (b) in November 2005, when most of the dendroecological sampling was carried out. In photograph a) the area affected by the studied avalanche has been demarcated. To the left-hand side in the same image, another avalanche released spontaneously almost at the same time as the main avalanche, but did not reach the channeled sector of the track.

branches and scarred trunks, in March 2004. We revisited the site in November 2005 and sampled 32 additional trees located in several sectors of the avalanche track using two different sampling strategies. First, we sampled trees with clear external evidence of past avalanches along the track ("selective sampling"), which allowed us to capture as much dendrochronological information as possible about recent and past avalanche events (Table 1). Second, we sampled all trees, regardless of their condition, in a rectangular plot perpendicular to the run-out zone of the 2002 event ("plot sampling"), which permitted us to determine both the proportion of trees growing in a particular area containing evidence of past events and the variation in damage intensity along the sampling plot. We did not sample trees above the run-out area of the 2002 event as we only found very young trees, most of which were distant from the avalanche track. The sampling sectors included the track and borders of the 2002 event (at the altitude of the run-out area), a section of the valley below the 2002 event run-out area, and a control area approximately $150 \mathrm{~m}$ east of the avalanche track (Table 1 ). The control area has an aspect, altitude and steepness similar to that of the run-out zone of the avalanche, but exhibits no signs of disturbance. A diagram of the avalanche track, including the accumulation (or release), transition and run-out zones, is provided in Fig. 4.

\subsection{Dendrochronological analyses}

All samples were prepared following standard dendrochronological techniques (Stokes and Smiley, 1968). With the exception of the increment cores taken from the control area, cross sections were collected along the track as they provide a more accurate and complete record of past 
Table 1. Nothofagus pumilio trees sampled at Cerro Ventana. Two sampling designs were used: "selective sampling" and "plot sampling", and both designs included sectors of the track and borders of the avalanche. A control area located approximately $150 \mathrm{~m}$ east of the avalanche track, which has an aspect, altitude and steepness similar to that of the studied avalanche track was also studied.

\begin{tabular}{llcccc}
\hline Sampling design & Sector & Number of trees sampled & Dead trees & Cross sections & Increment cores \\
\hline \multirow{2}{*}{ Selective sampling } & track & 12 & 0 & 13 & 0 \\
& border & 3 & 0 & 4 & 0 \\
\multirow{2}{*}{ Plot sampling } & track & 18 & 4 & 21 & 0 \\
- & border & 6 & 0 & 9 & 0 \\
Total & control & 11 & 0 & 0 & 22 \\
\hline
\end{tabular}

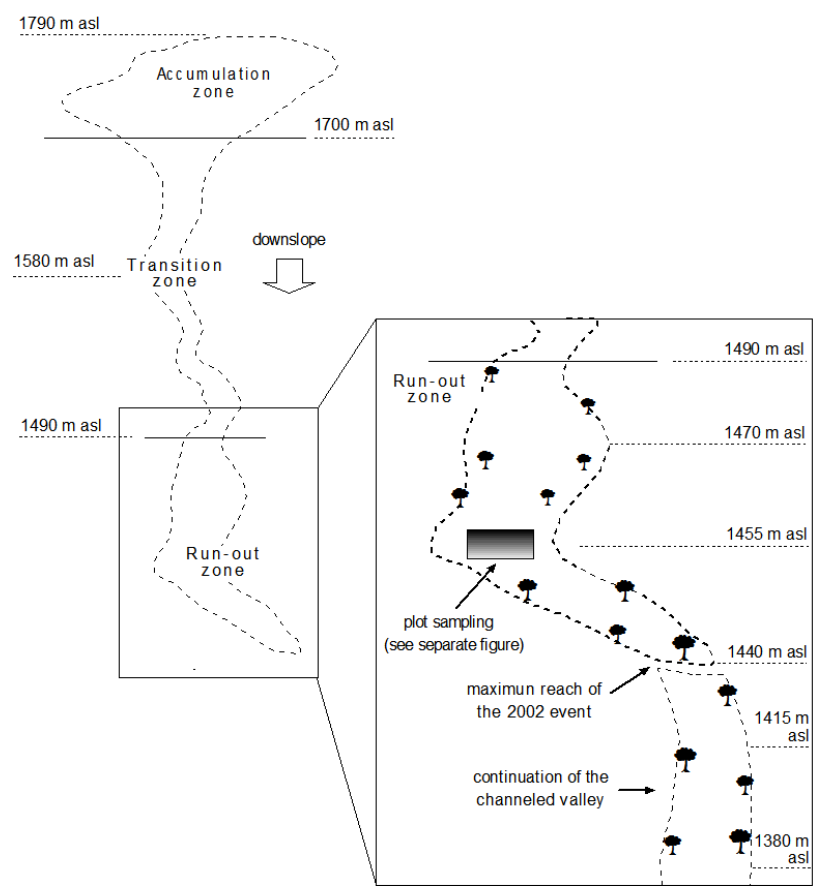

Fig. 4. Scheme of the studied avalanche track at Cerro Ventana. The contour line of the avalanche was established from a 2-D digitalization of the affected area, as documented in a photograph taken one day after the event (Fig. 3a). The sampling procedure was conducted in the run-out zone of the 2002 event and in a section of the valley downslope. Two sampling designs were used: "selective sampling" and "plot sampling".

avalanche events (Carrara, 1979; Casteller et al., 2007). Samples were dated following Schulman's (1956) convention for the Southern Hemisphere, assigning to each tree ring the year in which radial growth started. On each cross section, a total of four radii were measured: one in the upslope direction, one in the downslope direction and two opposite radii perpendicular to the slope. Tree-ring widths were measured to the nearest $0.01 \mathrm{~mm}$. Individual tree-ring series were crossdated against a master chronology developed from trees in the control area. To detect dating errors (i.e. missing or false rings) the cross-dating quality was evaluated using the program COFECHA (Holmes, 1983) and the graphical function of the program TSAP-Win (Rinn, 1996). The master treering chronology from the control sector was developed using the program ARSTAN (Cook, 1985).

For each cross-dated sample we assessed: (1) the years for exposed and hidden (i.e. overgrown by the stem) scar formations (e.g. Mears, 1975; Dubé et al., 2004), (2) abrupt growth changes (e.g. Butler, 1985; Rayback, 1998) and (3) changes in eccentricity (e.g. Schweingruber, 1996; Casteller et al., 2007). We calculated abrupt growth changes with the program IMPACT (Grissino-Mayer et al., 1997), which uses tree-ring measurement series to compare mean growth before and after a disturbance. We selected a time span starting three years before and ending two years after the event. The changes in radial tree growth that we used as thresholds to define positive and negative abrupt growth changes were $200 \%$ and $30 \%$, respectively. Changes in eccentricity were calculated using the annual eccentricity index (Iex; Schweingruber, 1996), using a threshold of $100 \%$ to define significant values.

Iex $=\frac{\text { tree }- \text { ring widths upslope side }}{\text { tree }- \text { ring widths downslope side }}$

\subsection{Avalanche simulations}

We used the numerical avalanche dynamics models AVAL1D (Bartelt et al., 1999; Christen et al., 2002) and RAMMS (Christen et al., 2005; Christen et al., 2007; Gruber and Bartelt, 2007) to simulate the 2002 Cerro Ventana avalanche event. AVAL-1D is a one-dimensional, well-calibrated, and state-of-the-art tool in avalanche hazard mapping that tracks the motion of an avalanche from initiation to runout. The track profile and the flow width must be specified. RAMMS (Rapid Mass Movements) is a two-dimensional model that simulates avalanche motion in complex three-dimensional terrain. Unlike AVAL-1D, the flow width in RAMMS is not specified, but determined by the model. Therefore, it is especially valuable in non-canalized terrain, where the predefinition of the flow width is difficult to determine. In order 

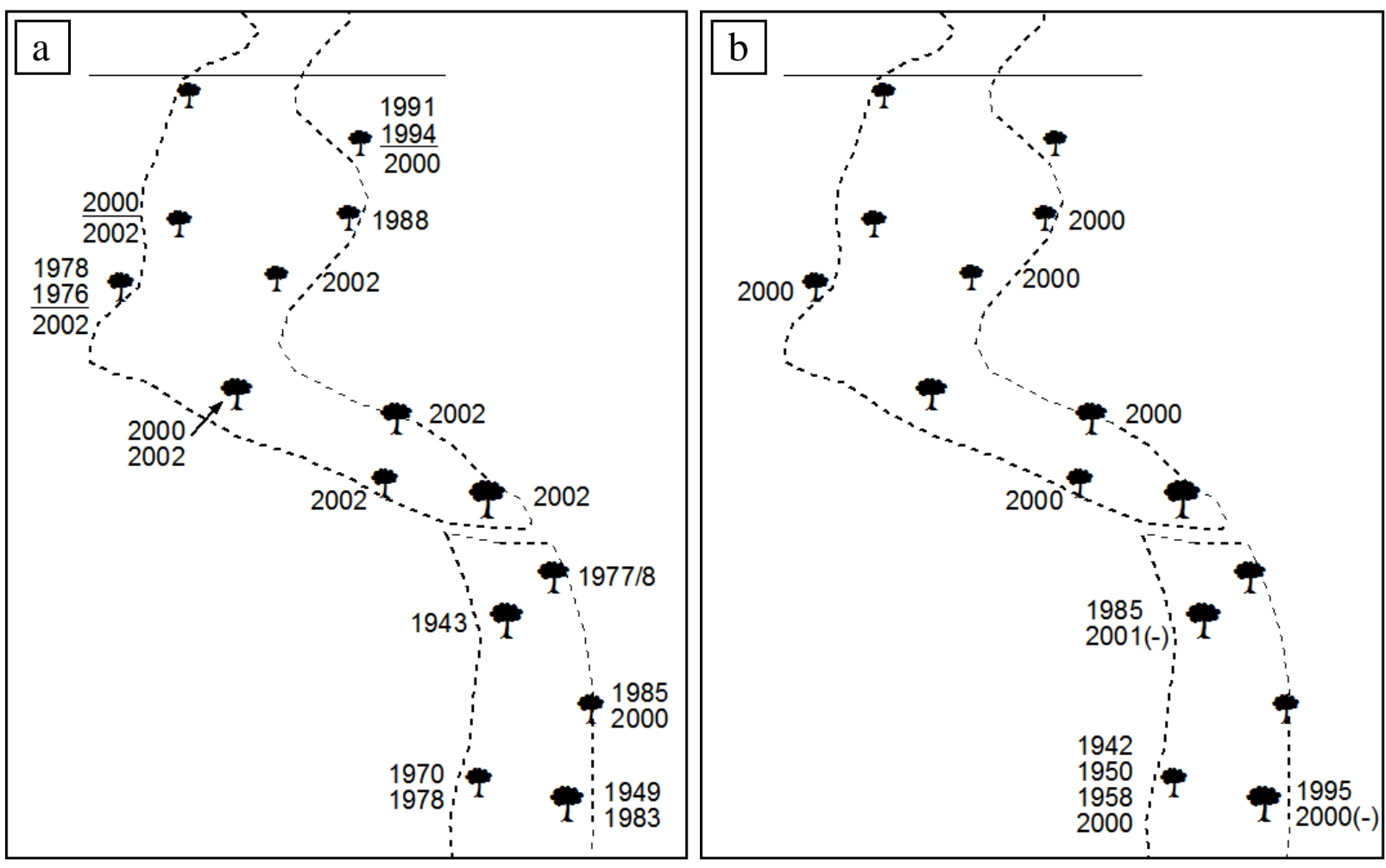

Fig. 5. Detail of the run-out zone of the 2002 avalanche event and a section of the valley downslope (see Fig. 4), in which the spatial distribution of the sampled trees is shown. Figure (a) indicates for each tree the years with scars and eccentricity variations (the latter underlined), whereas figure (b) shows the years with positive and negative (the latter indicated with a minus sign) abrupt growth changes.

Table 2. Changes in radial growth for selected trees in the track and borders of the sampling plot. The calculations were done with the program IMPACT using time spans starting three years before and ending two years after the 2002 event. The orientation of each analyzed radius in relation to the slope is indicated.

\begin{tabular}{ccccc}
\hline Plot sector & Sample code & Growth variation (\%) & Radius orientation & Observations \\
\hline Border & ve01 & 37,7 & Downslope & branch \\
\hline \multirow{6}{*}{ Track } & ve07 & 464,7 & Side & \\
& ve08 & 529,8 & Side & \\
& ve11 & 633,9 & Side & branch \\
& ve12 & 461,6 & Upslope & \\
& ve13 & 380,1 & Side & \\
& ve17 & 14,9 & Side & \\
& ve20 & 445,8 & Side & \\
\hline \multirow{2}{*}{ Border } & ve21 & 469,1 & Side & \\
& ve22 & 95,7 & Side & \\
& ve22b & 444,6 & Side & \\
\hline
\end{tabular}

to take advantage of the strengths of both numerical models (one-dimensional and two-dimensional), we simulated the Cerro Ventana event using both AVAL-1D and RAMMS.

AVAL-1D predicts run-out distances, flow velocities and impact pressures of both flowing and powder snow avalanches at every point of a specified avalanche track. The flowing avalanche model solves a system of differential equations, describing the depth-averaged conservation of mass and momentum equations using an upwinded finite difference scheme (Sartoris and Bartelt, 2000). The flow rheology 

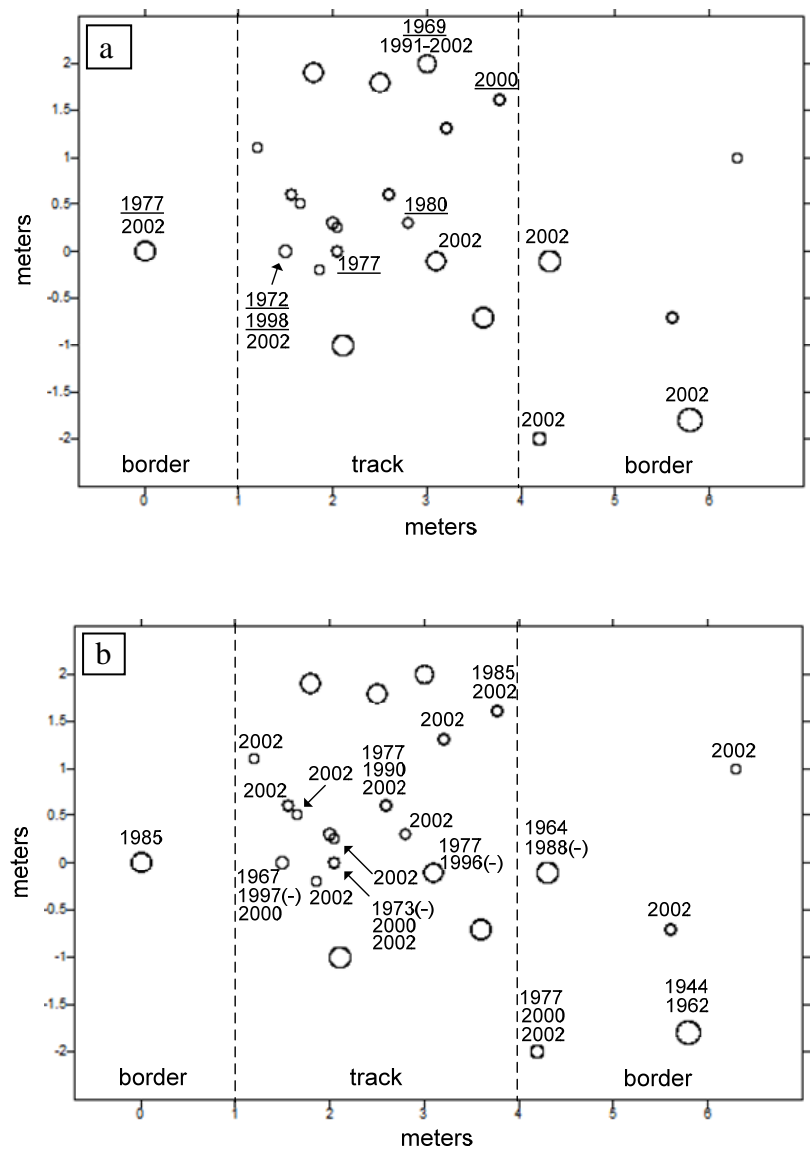

Fig. 6. Spatial distribution of the trees sampled in the plot (see Fig. 4). Figure (a) shows the years with scars and eccentricity variations (the latter underlined), whereas figure (b) indicates the years with positive and negative (the latter indicated with a minus sign) abrupt growth changes for each tree. The symbols for the trees are proportional to the diameter of the trunks at their base.

is a hydraulics-based model and divides avalanche frictional resistance into a dry Coulomb-type friction $\mu$ and a viscous resistance $\xi$, which varies with the square of the flow velocity. The model has been adjusted using forest parameters identified by Bartelt and Stöckli (2001), who showed how the dry Coulomb and viscous friction varied as a function of avalanche size and forest interaction mechanisms (branch bending, trunk fracture and tree uprooting). Required input parameters for AVAL-1D are: (1) distance-altitude $(x-y)$ profile of the avalanche path, (2) avalanche width along the path, (3) release area and release height, and (4) friction parameters. The area and mean altitude values of the release area were $17100 \mathrm{~m}^{2}$ and $1715 \mathrm{~m}$ a.s.l., respectively, and the observed snow height was $0.6 \mathrm{~m}$. The width of the avalanche was estimated from site observations. The friction parameters $\mu$ and $\xi$ were chosen according to the Swiss Guidelines (Salm et al., 1990) for wet snow avalanches, but then modified to account for forest interaction. The software package
RAMMS combines three-dimensional process modules for snow avalanches, debris flows and rockfalls with protection and visualization modules. Because the system is linked to a GIS environment, RAMMS is a powerful tool for hazard mitigation studies in mountainous regions that are affected by gravity driven, rapid mass movements. The avalanche module predicts avalanche run-out distances, flow velocities and impact pressures in general three-dimensional terrain using a finite volume scheme to solve the shallow water equations. Required input parameters for RAMMS are: (1) a digital elevation model (DEM), (2) information about size, location and snow height of the release area, (3) friction parameters, and (4) a geo-referenced map or aerial photo to overlay the DEM. The simulations with RAMMS were based on a $30 \mathrm{~m}$ digital terrain model generated from ASTER satellite data. An accurate estimation of the size and location of the avalanche release area, which is critical for a good simulation, was achieved by (1) interpreting photographs taken a few days after the September 2002 event, and (2) from DEM and satellite images interpretations. A polygon shape file of the release area was created using GIS software. The same value of $0.6 \mathrm{~m}$ was used as release height. Different friction parameter combinations were analyzed to find a best fit for the Cerro Ventana event.

\section{Results}

\subsection{Dendrochronological approach}

\subsubsection{Selective sampling of avalanche-impacted trees along the track}

We found tree-ring evidence of the 2002 Cerro Ventana event on seven out of the ten trees sampled along the run-out zone of the avalanche (Fig. 5). In all cases, the evidence was in the form of scars; we did not observe eccentricity variations or abrupt growth changes (AGC) in these trees related to the 2002 event. As was expected, no dendrochronological evidence of the 2002 event was recorded below its lower altitudinal limit of $1440 \mathrm{~m}$ (Fig. 4). Tree-ring evidences considering all fifteen sampled trees along the track suggest the occurrence of avalanches prior to year 2002. In particular, clear signs of avalanche disturbance were recorded for the year 2000 consisting of three scars, a marked change in eccentricity and seven AGC (both positive and negative; Fig. 5). Other years with less frequent avalanche indicators are 1943, 1949, 1978, 1985 and 1991. The trees recording avalanche activities during these years are distributed at altitudinal levels ranging from $1380 \mathrm{~m}$ to $1490 \mathrm{~m}$ a.s.l. (Fig. 4).

\subsubsection{Plot sampling perpendicular to the avalanche track}

Tree-ring evidences of the 2002 avalanche event were recorded in nineteen out of the twenty-four sampled trees: seven trees had scars and thirteen exhibited positive AGC. 

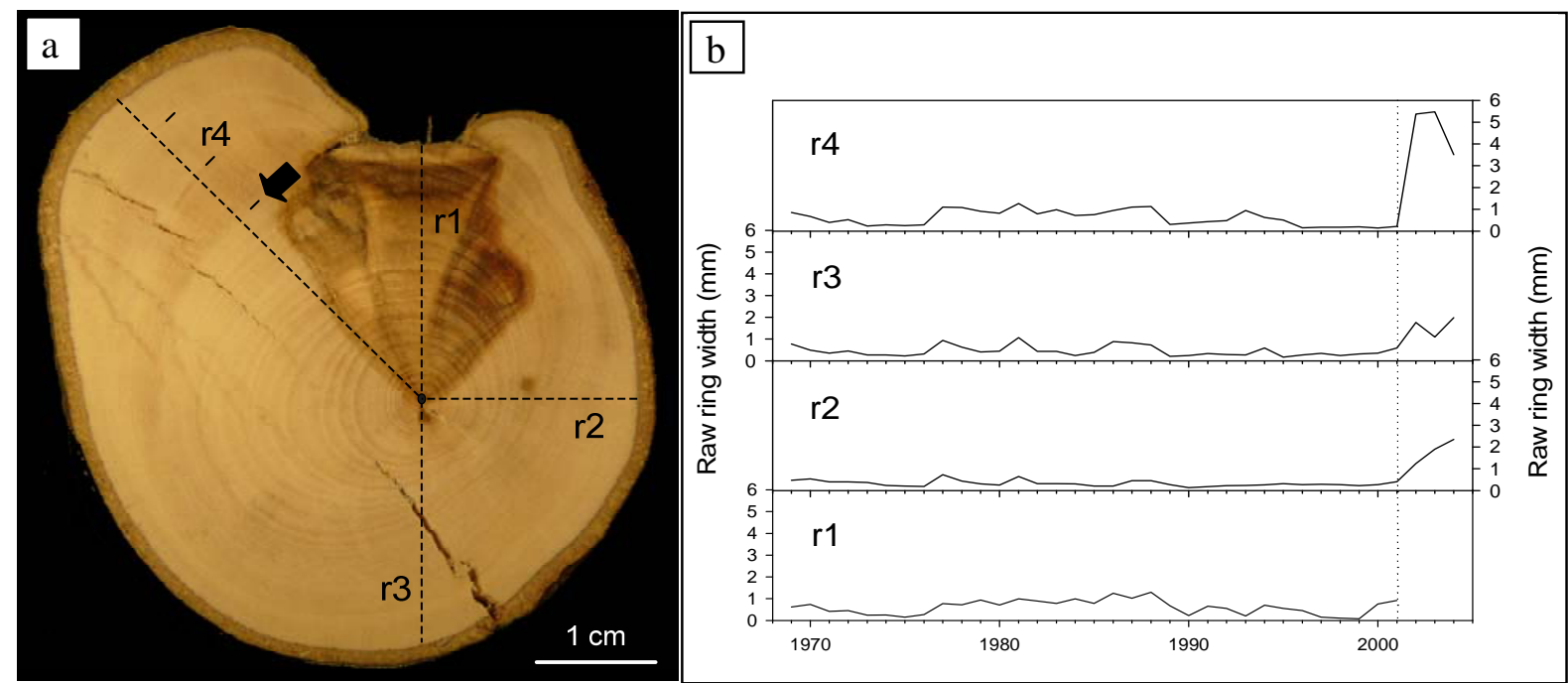

Fig. 7. (a) Cross section of N. pumilio showing evidence of the 2002 avalanche event. Four radii were measured: r1 is oriented upslope, r3 is oriented downslope, and $\mathrm{r} 2$ and $\mathrm{r} 4$ are oriented to each side. In figure (b) the ring widths of the four radii are displayed. The last year of undisturbed growth is 2001 (dotted line). The scar occurring in 2002 caused a growth termination on r1 and subsequent abrupt growth changes on the rest of the radii.

Table 3. Input parameters and results of the AVAL-1D simulations. The observed values of the 2002 event are provided at the base of the table for comparison.

\begin{tabular}{cccccc}
\hline Simulation & $\begin{array}{c}\text { Release height }(\mathrm{m}), \\
\mu \text { and } \xi\left(\mathrm{ms}^{-2}\right)\end{array}$ & $\begin{array}{c}\text { Max height } \\
(\mathrm{m})\end{array}$ & $\begin{array}{c}\text { Max velocity } \\
\left(\mathrm{ms}^{-1}\right)\end{array}$ & $\begin{array}{c}\text { Stopping altitude } \\
(\mathrm{m} \text { a.s.1. })\end{array}$ & $\begin{array}{c}\text { Mass above } \\
1440 \mathrm{~m} \text { a.s.1. }(\%)\end{array}$ \\
\hline 1 & $0.6 / 0.42 / 400$ & 3.20 & 9.45 & 1436 & 87 \\
2 & $0.6 / 0.42 / 700$ & 2.95 & 12.40 & 1420 & 75 \\
3 & $0.6 / 0.42 / 1000$ & 2.50 & 14.70 & 1407 & 64 \\
4 & $0.6 / 0.44 / 400$ & 3.35 & 9.20 & 1443 & 93 \\
5 & $0.6 / 0.44 / 700$ & 3.15 & 12.10 & 1427 & 75 \\
6 & $0.6 / 0.44 / 1000$ & 2.80 & 14.35 & 1419 & 96 \\
7 & $0.6 / 0.47 / 400$ & 3.30 & 8.90 & 1451 & 92 \\
8 & $0.6 / 0.47 / 700$ & 3.20 & 11.65 & 1440 & 65 \\
9 & $0.6 / 0.47 / 1000$ & 3.00 & 13.80 & 1432 & 79 \\
10 & $1.85 / 0.47 / 700$ & 6.40 & 18.40 & 1395 & 100 \\
\hline
\end{tabular}

One individual exhibited both types of disturbance (Fig. 6). Variations in eccentricity related to the 2002 event were not observed. Four of the five trees that did not exhibit any of the above-mentioned tree-ring indicators died in 2002 (Table 1).

In relation to the spatial distribution of evidences in the plot, scars were recorded in both the track and borders (Fig. 6a), whereas AGC were more common in the track as compared to the borders (Fig. 6b). Eccentricity variations, scars and AGC suggesting previous avalanche events are concentrated in the years 1977, 1985, 1991 and 2000.

Changes in radial growth following the 2002 event varied considerably both among trees as well as within radii of individual trees. Some radii reached positive AGC of over $600 \%$, whereas others had values below $15 \%$ (Table 2). As observed in Fig. 7, the growth termination of the radius oriented upslope due to a scar in 2002 hinders the evaluation of changes in stem eccentricity associated with this event. However, marked changes in radial growth on the radii not affected by the scar make AGC more conspicuous. 

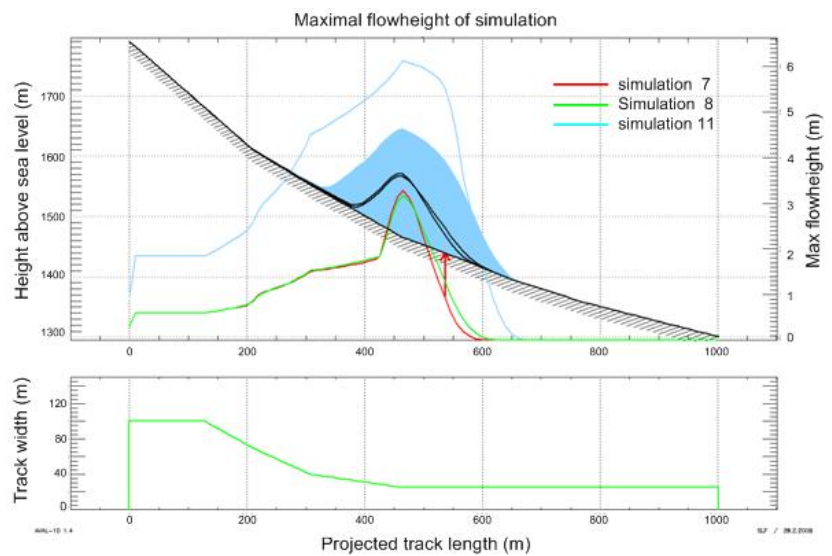

Fig. 8. Numerical simulations carried out with the program AVAL1D for the 2002 Cerro Ventana event. Maximal flow heights and runouts for simulations 7,8 and 11 are shown. The red arrow depicts the runout distance of the observed event.
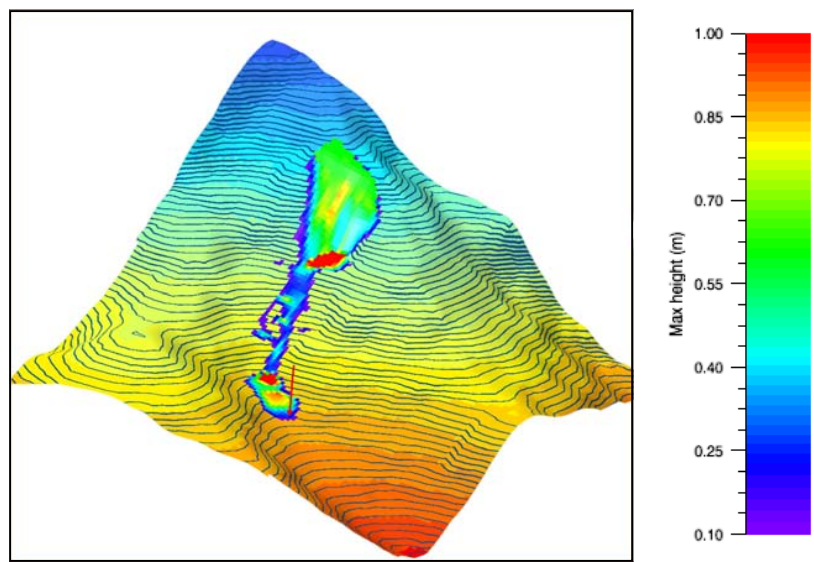

Fig. 9. Cerro Ventana topography displayed in RAMMS showing the maximum flow height of simulation 3 . A coloured contour line image is mapped over the surface. The red arrow shows the runout distance of the observed avalanche, which is coincident with the simulated value.

\subsection{Avalanche simulations}

\subsubsection{AVAL-1D}

The Cerro Ventana avalanche is estimated to have a release volume of slightly over $10000 \mathrm{~m}^{3}$. In the simulations a fracture height of $0.6 \mathrm{~m}$ was employed, providing volumes similar to the observed ones (simulation volume $10300 \mathrm{~m}^{3}$ ). Several simulations with different friction parameter combinations were performed using this starting volume. Values of $\mu=0.42,0.44$ and 0.47 were used for the dry friction coefficient; values of $\xi=400,700$ and $1000 \mathrm{~ms}^{-2}$ for the viscous friction coefficient (Table 3). These values are typical for small avalanches (volumes less than or equal to $10000 \mathrm{~m}^{3}$ ) such as the 2002 Cerro Ventana event. The track width at the run-out zone of the simulated event was $25 \mathrm{~m}$, corresponding to the observations. The projected length of the simulated avalanches and their altitudinal difference between runout and release area were approximately $600 \mathrm{~m}$ and $350 \mathrm{~m}$, respectively (Fig. 8). Both values agree well with those recorded for the documented event in 2002. Because no velocity observations are available, the simulation results were compared with the avalanche event by looking at the deposition heights and the runout distance.

Simulations 4, 7 and 8 took into account a release height of $0.6 \mathrm{~m}$ and yielded the best results in relation to the altitude where the avalanches stopped: $1443 \mathrm{~m}, 1451 \mathrm{~m}$ and $1440 \mathrm{~m}$, respectively (Table 3). Velocities between $8.90 \mathrm{~ms}^{-1}$ and $11.65 \mathrm{~ms}^{-1}$ and flow heights between $3.20 \mathrm{~m}$ and $3.35 \mathrm{~m}$ were obtained for these simulations (Table 3). However, the deposition heights are considerably lower than the observed value of $7 \mathrm{~m}$. A rough estimation of the overrun area $\left(\sim 35000 \mathrm{~m}^{2}\right)$ multiplied by a possible erodible snow height of $0.6 \mathrm{~m}$ resulted in an additional eroded volume of $21000 \mathrm{~m}^{3}$. Simulations 10 and 11 were made with an increased release height of $1.85 \mathrm{~m}$, taking snow erosion into account, resulting in a new total volume of $31300 \mathrm{~m}^{3}$ $(10300+21000)$. Friction parameter combinations of Simulations 7 and 8 were used in Simulations 10 and 11. The obtained deposition height of $6.15 \mathrm{~m}$ of Simulation 11, together with a runout altitude of $1415 \mathrm{~m}$ a.s.l. are very close to the observed deposition height of $7 \mathrm{~m}$ and the runout altitude of 1440 m a.s.l. (Fig. 8).

\subsubsection{RAMMS}

Four simulations were conducted using a release height of $0.6 \mathrm{~m}$ (release volume of $10300 \mathrm{~m}^{3}$ ) and the following friction coefficients: 1) $\mu=0.47, \xi=1000 \mathrm{~ms}^{-2}$; 2) $\mu=0.42$, $\xi=1000 \mathrm{~ms}^{-2}$; 3) $\mu=0.38, \xi=1000 \mathrm{~ms}^{-2}$; and 4) $\mu=0.40$, $\xi=700 \mathrm{~ms}^{-2}$ (Fig. 10). The values for the dry friction coefficient $\mu$ were chosen according to the AVAL-1D results. Since two-dimensional simulations usually lead to smaller calculated flow heights, the $\xi$ parameter was slightly increased as compared to the values used in the AVAL-1D simulations. An erodible snow layer of $0.6 \mathrm{~m}$ was incorporated in Simulation 4, which resulted in an additional eroded snow volume of $21000 \mathrm{~m}^{3}$ and therefore in a total avalanche volume of $31300 \mathrm{~m}^{3}$ (see AVAL-1D Simulations 10 and 11 in Sect. 4.2.1).

The results show that the maximum simulated snow heights along the track vary from $1.95 \mathrm{~m}$ to $3.5 \mathrm{~m}$, values considerably lower than the observed $7 \mathrm{~m}$. The modelled deposition heights are too small because the flow widths are too large (Fig. 10). The run-out altitude given by the model for Simulation 3 (Fig. 9) is coincident with the observed value of $1440 \mathrm{~m}$ and varies $12 \mathrm{~m}$ upslope for Simulation 2, and $9 \mathrm{~m}$ downslope for Simulation 4. Simulated maximum velocities range from $15.40 \mathrm{~ms}^{-1}$ to $17.85 \mathrm{~ms}^{-1}$ (Fig. 10); no observed 

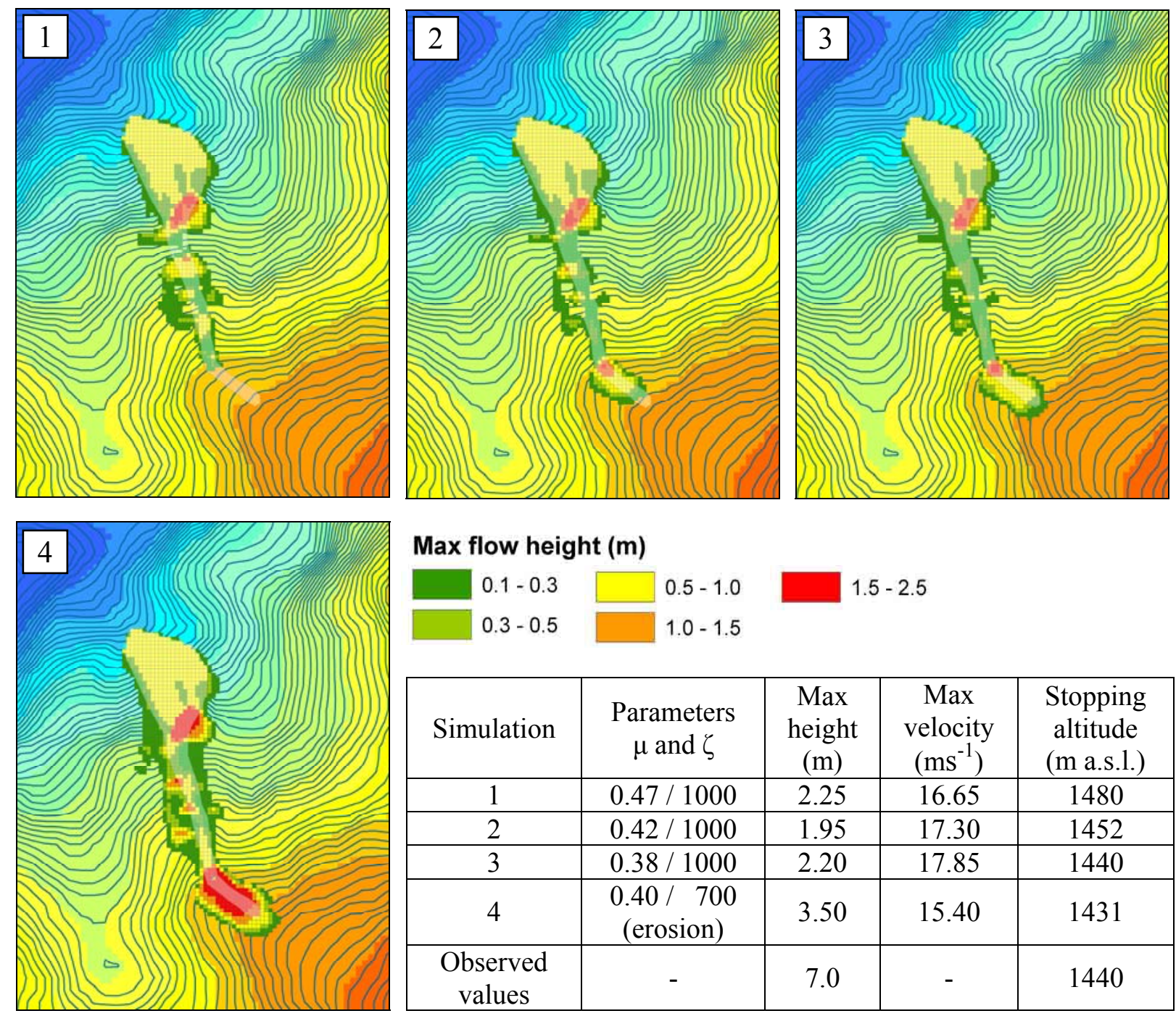

\section{Max flow height (m)}

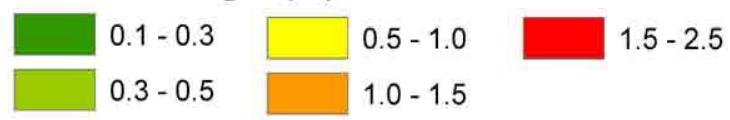

\begin{tabular}{|c|c|c|c|c|}
\hline Simulation & $\begin{array}{c}\text { Parameters } \\
\mu \text { and } \zeta\end{array}$ & $\begin{array}{c}\text { Max } \\
\text { height } \\
(\mathrm{m})\end{array}$ & $\begin{array}{c}\text { Max } \\
\text { velocity } \\
\left(\mathrm{ms}^{-1}\right)\end{array}$ & $\begin{array}{c}\text { Stopping } \\
\text { altitude } \\
(\mathrm{m} \text { a.s.1.) }\end{array}$ \\
\hline 1 & $0.47 / 1000$ & 2.25 & 16.65 & 1480 \\
\hline 2 & $0.42 / 1000$ & 1.95 & 17.30 & 1452 \\
\hline 3 & $0.38 / 1000$ & 2.20 & 17.85 & 1440 \\
\hline 4 & $\begin{array}{c}0.40 / 700 \\
\text { (erosion) }\end{array}$ & 3.50 & 15.40 & 1431 \\
\hline $\begin{array}{c}\text { Observed } \\
\text { values }\end{array}$ & - & 7.0 & - & 1440 \\
\hline
\end{tabular}

Fig. 10. Numerical simulations carried out with the program RAMMS for the 2002 Cerro Ventana event. Maximal flowheights for simulations 1 to 4 are shown. A colored contour line image is mapped over the surface. The outline of the observed avalanche event is depicted as a semi-transparent polygon.

data on this parameter are available for comparison with the model results. Even with a model that includes snow entrainment, it is not possible to correctly simulate the deposition heights of over $7 \mathrm{~m}$ with a $30 \mathrm{~m}$ DEM.

\section{Discussion}

The information collected in relation to the 2002 Cerro Ventana avalanche allowed us to numerically simulate this event. Input parameters for running model simulations, such as precise location and size of the release area, in addition to its snow height, have rarely been recorded for snow avalanches in the Southern Andes (Leiva et al., 2007). However, this information was available for the Cerro Ventana event and allowed us to simulate the spatial extent of the avalanche as well as to determine maximal flow heights and velocities along the avalanche track. To validate the results of the numerical models, the maximum extent of the event was inferred from dendrochronological methods and the maximal flow height at the run-out zone of the avalanche was determined in-situ. Friction coefficients $\mu$ and $\xi$ used by the models AVAL-1D and RAMMS were adjusted by choosing the combination that best fit to the observations. According to the simulations conducted with RAMMS, snow erosion was a significant process in the 2002 event (Sovilla et al., 2006).

In the European Alps, one-dimensional numerical avalanche dynamics models employ well-calibrated friction parameters (Bartelt et al., 1999). Extreme avalanches 
use values of $\mu=0.16$ and $\xi=3000 \mathrm{~ms}^{-2}$, whereas small, wet snow avalanches apply higher friction coefficients up to $\mu=0.43$ and $\xi=400 \mathrm{~ms}^{-2}$. However, the parameters $\mu$ and $\xi$ also depend on track characteristics such as elevation, roughness and channel geometry, as well as on the avalanche return period and release volume. We applied wet snow friction parameters (AVAL-1D: $0.42<\mu<0.47$ and $400<\xi<1000 \mathrm{~ms}^{-2}$; RAMMS: $0.38<\mu<0.47$ and $700<\xi<1000 \mathrm{~ms}^{-2}$ ) for the Cerro Ventana event. In comparison to the friction values applied in the European Alps, the chosen range was therefore in good agreement. Slightly larger $\mu$ values were required to model the observed runout distance with AVAL-1D.

The principal limitation for implementing the numerical models was the low resolution of the topographical model (ASTER DEM) available for the region. The low resolution overlooks the topographic features that funneled the avalanche along the narrow path, resulting in a lower simulated snow deposition height at the run-out zone (approximately $3 \mathrm{~m}$ ) than what was actually recorded (over $7 \mathrm{~m}$ ). Previous numerical simulations of snow avalanches in the Andes (Furdada et al., 2002) have reported similar problems in relation to DEM resolutions. One possibility to overcome this limitation is to employ topographical models from aerial photographs or high-resolution satellite images, which resolve surface details less than $10 \mathrm{~m}$ in size. The lack of a high resolution DEM hampered the assessment of the lateral spreading of the avalanche in the runout zone.

Our results support the analysis of tree rings from $N$. pumilio to precisely date and spatially determine the extent of past snow avalanches in the Patagonian Andes (Mundo et al., 2007). Selected living trees with visible damage provided the most complete record of past avalanche occurrences as well as the extent of the events along the track. Alternatively, sampling young, relatively-flexible trees in plots perpendicular to the track provided avalanche evidence for most of the trees, but mainly for recent events. Trees sampled below the 2002 run-out area preserve more evidence of older avalanche events as compared to trees located above this area, which results from a loss of tree-ring evidence due to the 2002 and previous avalanche events. This lack of information about earlier events has been pointed out in other dendrogeomorphological studies dealing with snow avalanche reconstructions (Dubé et al., 2004; Carrara, 1979).

In addition to the 2002 event, we have preliminary evidence for avalanche activity at Cerro Ventana in the years 1943, 1949, 1977, 1978, 1985, 1991 and 2000 from dendrochronological evidences. However, due to the limited number of tree-ring indicators in these years, this information should be regarded cautiously. Only in the year 2000 there is abundant tree-ring evidence to confirm the occurrence of an avalanche. Information released by a nearby ski resort at Cerro Catedral reported a large slab avalanche in July 2000 (http://cabbat1.cnea.gov.ar/forense/publicaciones/ semin_2001/avalancha.pdf). Due to the proximity between
Cerro Ventana and Cerro Catedral $(9.3 \mathrm{~km})$ we consider the occurrence of an avalanche in year 2000 at our study site to be highly possible. Indeed, high snowpack instability was also reported at Cerro Catedral at the time of the 2002 Cerro Ventana avalanche.

Regional-scale hazard mapping is needed to reduce the avalanche-related risk in populated areas of the Andes (Furdada et al., 2000). Tree rings and model simulations provide a good combination for reconstructing past avalanche events in forested regions of the Patagonian Andes. In avalancheprone areas lacking historical records, dendrochronological methods provide a useful technique to validate and ground truth the numerical models. Although the combined application of both approaches will provide the most consistent reconstructions, studies in Andean regions devoid of trees will rely largely on numerical models (Gruber and Bartelt, 2007). Ultimately, advances in snow avalanche modeling and in tree-ring applications will provide reliable avalanche hazard maps for the southern Andes.

Acknowledgements. This research could not have been conducted without the support of several people. We are especially grateful to mountain guide Damian Yabrés, Jorge Bagur, Comandante Darío Altamirano and Professor Maximiliano Schneider, for providing valuable information on the avalanche event at Cerro Ventana. Likewise, we thank the Ente Regulador de Cerro Catedral for the snow profiles and climatic data made available to us. Erin Gleeson is kindly acknowledged for the proof-reading of the paper. We would like to show gratitude to the reviewers for providing very useful comments, which helped us considerably in improving the paper. This research was supported by the Swiss Federal Institute for Snow and Avalanche Research, the Argentinean Agency for the Promotion of Science and Technology (PICTR02-186), and the Projects CRN03 and CRN2047 from the Inter-American Institute for Global Change Research (IAI). The latter project is funded by grant CRN II \# 2060, which is supported by the US National Science Foundation (Grant GEO-0452325).

Edited by: M. Bollschweiler

Reviewed by: two anonymous referees

\section{References}

Bartelt, P., Salm, B., and Gruber, U.: Calculating densesnow avalanche runout using a Voellmy-fluid model with active/passive longitudinal straining, J. Glaciol., 45(150), 242-254, 1999.

Bartelt, P. and Stöckli, V.: The influence of tree and branch fracture, overturning and debris entrainment on snow avalanche flow, Ann. Glaciol., 32, 209-216, 2001.

Bollschweiler, M., Stoffel, M., Ehmisch, M., and Monbaron, M.: Reconstructing spatio-temporal patterns of debris-flow activity using dendrogeomorphological methods, Geomorphology, 87, 337-351, 2007.

Burrows, C. J. and Burrows, V. L.: Procedures for the study of snow avalanche chronology using growth layers of woody plants, 
Boulder: University of Colorado, Institute of Arctic and Alpine Research occasional paper, 23, 54 pp., 1976.

Bustos, R. M., De la Cruz, S., Magaldi, D., Martínez, H., Schneider, M.: Peritaje técnico (experts' testimony), Oral presentation, San Carlos de Bariloche, 2003.

Butler, D. R.: Vegetational and geomorphic change on snow avalanche paths, Glacier National Park, Montana, USA, Great Basin Nat., 45(2), 313-317, 1985.

Butler, D. R., Oelfke, J. G., and Oelfke, L. A.: Historic rockfall avalanches, northeastern Glacier National Park, Montana, USA, Mt. Res. Dev., 6(3), 261-271, 1986.

Carrara, P. E.: The determination of snow avalanche frequency through tree-ring analysis and historical records at Ophir, Colorado, Geol. Soc. Am. Bull., 90 (8), 773-780, 1979.

Casteller, A., Stöckli, V., Villalba, R., and Mayer, A. C.: An evaluation of Dendroecological Indicators of Snow Avalanches in the Swiss Alps, Arct. Antarct. Alp. Res., 39(2), 218-228, 2007.

Christen, M., Bartelt, P., and Gruber, U.: AVAL-1D: An avalanche dynamics program for the practice, Proceedings of the International Congress Interpraevent 2002 in the Pacific Rim, Matsumoto, Japan, 715-725, 2002.

Christen, M., Bartelt, P., and Gruber, U.: Numerical calculation of snow avalanche runout distances, edited by Soibelman, L. and Pena-Mora, F., Proc. of the 2005 Computing in Civil Engineering International Conference, Cancun, Mexico, 11 pp., 2005.

Christen, M., Bartelt, P., and Gruber, U.: Modelling avalanches, GEOconnexion International Magazine, 6(4), 38-39, 2007.

Cook, E. R.: A Time Series Analysis Approach to Tree-Ring Standardization, Ph.D. Dissertation, Laboratory of Tree-Ring Research, University of Arizona, Tucson, 171 pp., 1985.

Dubé, S., Filion, L., and Hétu, B.: Tree-Ring Reconstruction of High-Magnitude Snow Avalanches in the Northern Gaspé Peninsula, Québec, Canada, Arct. Antarct. Alp. Res., 36 (4), 555-564, 2004.

Furdada, G., Martínez, H., Leiva, J. C., and Foerster, M.: Reducción del riesgo de avalanchas de nieve: el ejemplo de la estación de esquí de Las Leñas, Actas XXa Reunión Científica de Geofísica y Geodesia de la Asociación Argentina de Geofísica y Geodesia (AAGG), 264-268, 2000.

Furdada, G., Naaim, M., and Martinez, H.: Calibration and application of the MN2D dynamics model to the avalanches of Las Leñas (Argentina), Nat. Hazard. Earth Sys. Sci., 2, 221-226, 2002.

Grissino-Mayer, H. D., Holmes, R. L., Fritts, H. C.: The International Tree-Ring Data Bank Program Library Manual, Laboratory of Tree-Ring Research, The University of Arizona, Tucson, 75-87, 1997.

Gruber, U. and Bartelt, P.: Snow avalanche hazard modelling of large areas using shallow water numerical methods and GIS, Environ. Modell. Softw., 22, 1472-1481, 2007.

Holmes, R. L.: Computer-assisted quality control in tree-ring dating and measurement, Tree-Ring Bull. 43, 69-75, 1983.

Holtmeier, F. K.: Geological aspects of timberline in northern and central Europe, Arct. Alp. Res., 5 (3), A45-A54, 1973.

Hupp, C. R.: Dendrogeomorphic Evidence of Debris Flow Frequency and Magnitude at Mount Shasta, California, Env. Geol. Wat. Sci., 6(2), 121-128, 1984.

Leiva, J. C. and Martínez, H.: Estudio de las presiones y velocidades de impacto de la nieve sobre cobertizos en la Ruta Na- cional $\mathrm{N}^{\circ}$ 7, Technical report, Mendoza, 46 pp., 1998.

Leiva, J. C. and Martínez, H.: Estudio geocientífico aplicado al ordenamiento territorial de Puente del Inca, Anexo II, SEGEMAR, Mendoza, 5 pp., 2006.

Leiva, J. C., Martínez, H., Casteller, A., Novello, V., Bruce, R. H., Corvalán, E., Videla, V. H., Montepeluso, M. S.: Sistema de Control y Manejo de Vialidad Invernal de la Ruta Nacional 7, Etapa I 2006/7, Tercer Trimestre, Expediente 11334/05 DNV, Mendoza, 26 pp., 2007.

Leiva, J. C., Martínez, H., Cabrera, G., Casteller, A., Novello, V.: Sistema de Control y Manejo de Vialidad Invernal de la Ruta Nacional 7, Etapa I 2006/7, Cuarto Trimestre, Expediente 11334/05 DNV, Mendoza, 19 pp., 2008.

Maggioni, M. and Gruber, U.: The influence of topographic parameters on avalanche release dimension and frequency, Cold Reg. Sci. Technol., 37(3), 407-419, 2003.

Masiokas, M. H., Villalba, R., Luckman, B. H., Le Quesne, C., and Aravena, J. C.: Snowpack variations in the central Andes of Argentina and Chile, 1951-2005: Large-scale atmospheric influences and implications for water resources in the region, J. Climate, 19(24), 6334-6352, 2006.

Mears, A. I.: Dynamics of Dense Snow Avalanches Interpreted from Broken Trees, Geology, 3(9), 521-523, 1975.

Mundo, I. A., Barrera, M. D., and Roig, F. A.: Testing the utility of Nothofagus pumilio for dating a snow avalanche in Tierra del Fuego, Argentina, Dendrochronologia, 25, 19-28, 2007.

Norton, D. A., and Schönenberger, W.: The growth forms and ecology of Nothofagus solandri at the alpine timberline, Craigieburn Range, New Zealand, Arct. Alp. Res., 16(3), 361-370, 1984.

Perla, R. I. and Martinelli, M. M.: The avalanche handbook, USDA Forest Service Handbook, 489, 238 pp., 1978.

Rayback, S. A.: A dendrogeomorphological analysis of snow avalanches in the Colorado Front Range, USA, Phys. Geogr., 19(6), 502-515, 1998.

Rinn, F.: TSAP. Time series analysis and presentation. Version 3.0 reference manual, 262 pp., 1996.

Salm, B.: Lawinenkunde für den Praktiker, Schweizer Alpen Club, Bern, 148 pp., 1982.

Salm, B., Burkard, A., and Gubler, H.U.: Berechnung von Fliesslawinen, eine Anleitung für Praktiker mit Beispielen, Mitteilungen des Eidgenössischen Institutes für Schnee und Lawinenforschung 47, Davos, 38 pp.,1990.

Sartoris, G. and Bartelt, P.: Upwinded finite difference schemes for dense snow avalanche modelling, Int. J. Numer. Meth. Fl., 32(7), 799-821, 2000.

Schulman, E.: Dendroclimatic Change in Semiarid America, University of Arizona Press, Tucson, Arizona, 142 pp., 1956.

Schweingruber, F. H.: Tree Rings and Environment Dendroecology, Paul Haupt Verlag, Bern, 609 pp., 1996.

Sovilla, B., Burlando, P., and Bartelt, P.: Field experiments and numerical modelling of mass entrainment in snow avalanches, J. Geophys. Res-Earth, 111(3), F03007, doi:10.1029/2005JF000391, 2006.

Stoffel, M., Schneuwly, D., Bollschweiler, M., Lièvre, I., Delaloye, R., Myint, M., and Monbaron, M.: Analyzing rockfall activity (1600-2002) in a protection forest - a case study using dendrogeomorphology, Geomorphology, 68, 224-241, 2005.

Stokes, M. A. and Smiley, T. L.: An introduction to Tree-Ring Dating, University of Chicago Press, Chicago, 73 pp., 1968. 